DOI: https://doi.org/10.4796o/2303-7431.24.2020.120

UDK: $017.1(497.5)=124$ '0 4

$272-788(497.5)$

Izvorni znanstveni članak

Primljen 25. IX. 2020.

Prihvaćen 11. IV. 2021.

LuCIJA KRešić NACEVSKI

Sveučilište u Zagrebu, Fakultet hrvatskih studija

lucijakresico1@gmail.com

\title{
HAGIOGRAFSKI KODEKS PASIONAL MR 164: FLEKSIJA, DERIVACIJA I SINTAKSA IMENĀ U BIBLIJSKOME LATINITETU NE-BIBLIJSKIH TEKSTOVA. APPENDIX: PASSIO SANCTE BARBARE.
}

\section{Sažetak}

Hagiografski kodeks Pasional MR 164 smatra se najstarijim kodeksom Metropolitane, knjižnice Zagrebačke nadbiskupije. Tvoren je od dva dijela: temeljnom karolinškom Pasionalu naknadno je privezan beneventanski dodatak s kraćim tekstovima Secunda expositio super psalmum CXIX i Vita Marie Egipciace de Greko in Latinum translata. Nastanak hagiografskoga Pasionala datiran je analizama u 10. stoljeće, a smatra se da je napisan na istočnoj obali Jadrana, na ravenskome području. Beneventanski dio datirao je zabilješkom u tekstu sam njegov pisar, đakon Majon, u prva desetljeća 11. stoljeća. Pisan je na splitskome području, za potrebe splitske nadbiskupije i po nalogu nadbiskupa Pavla. Sadržajna analiza i sanktoral karolinškoga Pasionala dovode ga u svezu s ravenskom bazilikom Sant' Apollinare Nuovo, a jezična analiza potvrđuje da je jezik Pasionala biblijski latinitet ne-biblijskih tekstova. Ovaj rad obrađuje fleksiju, derivaciju i sintaksu imenā u okvirima biblijskoga latiniteta ne-biblijskih tekstova, isključivo karolinškoga Pasionala. Na primjerima se utvrđuje koliko je biblijski latinitet ne-biblijskih tekstova samostalan 
jezični idiom, i je li uopće, a koliko počiva na vulgarnome latinitetu. Kao dodatak glavnomu tekstu rada pridodana je transkribirana pasija svete Barbare.

Ključne riječi: biblijski latinitet; Pasional MR 164; srednjovjekovni latinitet; vulgarni latinitet

\section{Pasional MR 164 u svjetlu hrvatskoga ranosrednjovjekovlja}

Rano srednjovjekovlje je na hrvatskome teritoriju nesumnjivo iznjedrilo brojne latinske kodekse, od kojih su danas, nažalost, sačuvani uglavnom fragmenti. Nakon splitskih crkvenih sabora 925. i 928. godine, kada je zakonima propisana latinska crkvena liturgija, na dalmatinskim područjima morali su se upotrebljavati latinski kodeksi iz kojih se služilo bogoslužje. Tomu u prilog govore prvi sačuvani i brižno izrađeni kodeksi iz 11. stoljeća, koji pokazuju visok stupanj stiliziranosti. Ti su kodeksi morali imati svoje ranije uzore. Ustaljeni trendovi u iluminaciji kodeksa toga doba, kao i dalmatinska beneventana kojom se uglavnom pisalo, potvrđuju da su po samostanima i dvorovima postojali dobro uhodani skriptoriji s obučenim pisarima i iluminatorima. Osim Splitskoga evangelijara koji je nastao u 8. stoljeću na rimskome području (usp. Matijević, 2014: 76), danas nam je iz tih ranijih vremena očuvan još samo jedan kodeks, a to je latinski Passionale MR 164 (hrv. Pasional). Pasional MR 164. čuva se u Metropolitani, knjižnici Zagrebačke nadbiskupije, kao njezin najstariji kodeks. Sadržajno je tvoren od dvaju dijelova. Prvi je dio obimni karolinški Pasional (f. 1-227r) s hagiografskim tekstovima: passiones, vita, acta, gesta, miracula, uz lekcije iz evanđelja, propovijedi i govore. Drugi je dio naknadno privezan Pasionalu, pisan je dalmatinskom beneventanom na splitskome području, za potrebe splitske nadbiskupije i po nalogu nadbiskupa Pavla. Sadrži tekstove: Breviarium in Psalmos, Secunda expositio super psalmum cxix (f.258r-259r) i Vita Marie Egipciace de Greko in Latinum translata (f.259r-f.267v). Za razliku od prvoga, karolinškoga dijela kodeksa koji je datiran posredno analizama (usp. Krešić, 2015: 62), beneventanski je tekst posebnom 
bilješkom datirao i ubicirao sam njegov pisar, đakon Majon. U ovome radu raspravljat će se tek o nekim jezičnim aspektima karolinškoga dijela, pravoga Pasionala.

Jezičnom analizom Pasionala (usp. Krešić, 2015: 191) može se zaključiti da su hagiografski tekstovi pisani biblijskim latinitetom ne-biblijskoga teksta koji do sada nije bio predmet interesa hrvatske znanstvene zajednice. Uvidom u stranu literaturu razabiremo da se o toj temi tijekom prošloga stoljeća uvelike raspravljalo. Ipak, do danas nije zaključena rasprava o biblijskome latinitetu kao o posebnome jeziku. Ovaj rad obrađuje fleksiju, derivaciju i sintaksu imenā biblijskoga latiniteta ne-biblijskih tekstova, stavlja ih u suodnos s klasičnim, opisuje vulgarnolatinsku jezičnu bazu te ulazi u trag utjecaju i prijevodnim rješenjima s grčkoga i hebrejskoga jezika.

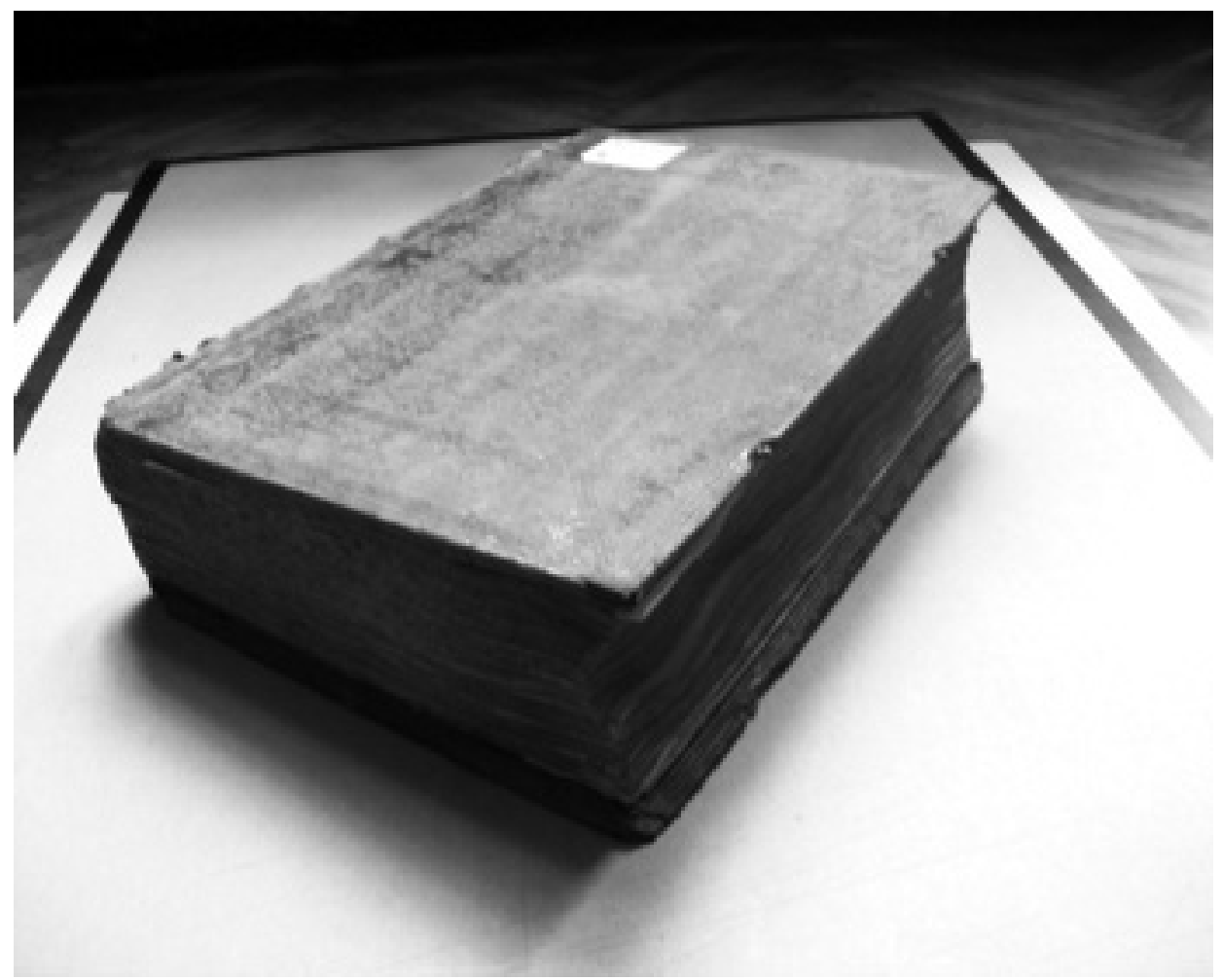

Slika 1: Pasional MR 164 u knjižnici Metropolitani 


\section{Generalne filološke karakteristike}

Analiza morfosintaktičke razine biblijskoga latiniteta Pasionala $M R$ 164 upućuje na određeni odmak od norme $\mathrm{SL}^{1}$, prema kojoj su prijedlozi promijenili značenje i postali dio analitičke deklinacije umjesto dotadašnje klasične, sintetičke. Klasični je deklinacijski sustav očuvan i nema većih osobitih odstupanja u pogledu zamjene deklinacija, broja ili roda imenica. Zašto u Vulgati i tekstovima pisanim biblijskim latinitetom (uglavnom) nije bilo većih morfoloških nepravilnosti vezanih za deklinaciju i konjugaciju, objašnjeno je postupkom sv. Jeronima. Naime, on i njegova prevoditeljska škola vršili su taj posao s osobitim marom pa su greške/propusti bili redovito i odmah uklanjani, a morfosintaktička razina ostala je na razini govornoga, vulgarnoga ${ }^{2}$ jezika koji je tada bio u upotrebi (usp. Plater - White, 1926: 65; Sheerin, 1996: 142). Stoga se ne može govoriti o velikim i radikalnim odstupanjima kakve bilježe imenice i glagoli u SL, prema kojima bi se otkrili tragovi lokalne zajednice. U radu će se razmatrati samo osobitosti imenā Pasionala. Uključeni su pregled fleksije, derivacije i sintaksa imena, a pod time mislimo na imenice, zamjenice i pridjeve.

\subsection{Fleksija imenica}

Generalne su morfološke osobitosti:

- grčki akuzativ (usp. Plater - White, 1926: 33; Blaise, 1955: 67), osobito vidljiv kod osobnih imena, primjerice beaten Agathen f.95r (usp. Plater - White, 1926: 33 - 35), beatam Agnen f. 87r, Demostren f. 159v, Cerimonen f. 97r.

\footnotetext{
SL skraćenica je za srednjovjekovni latinitet, VL za vulgarni latinitet, a KL za klasični latinitet.

2 Općenito se smatra da je termin vulgarni latinitet osobito nesretan izbor (sa skupa Latin Vulgaire - Latin Tardif, Oviedo, 2014.). Naime, nigdje u latinskoj literaturi ne nalazi se zabilježen latinski pojam koji bi se preveo takvim rješenjem. Prikladniji izraz bio bi pučki, govorni jezik jer pridjev vulgaran u hrv. jeziku znači prost, nepristojan, grub.

3 Sufiksacija imena i glagola u nekim se priručnicima (vidi Sheerin, 1996: 142) obrađuje pod morfološkim, a negdje pod leksičkim osobitostima (vidi Plater - White, 1926: 42 i dalje).
} 
- pojava dubleta (usp. Blaise, 1955: 67): nominativ gornje imenice dolazi u dvije inačice Agatha/Agathes, potom diacon/diaconus, beata Agnes, gen. Agnetis/Agne, ak. Agnem/Agnen

- akuzativ i ablativ na -em, -e kod imenica koji su u KL imale te padeže na -im, -i (usp. Blaise, 1955: 68; Grandgent, 1907: 152), primjerice: turrem/turre

- zbunjujuća upotreba ablativnoga završetka e, odnosno $i$, u 3. dekl. srednjega roda (usp. Blaise, 1955: 68): altare, nave/navi, mare/ mari, turre, contioni

- novi sufiksalni dočeci kod imenica, pridjeva, priloga i glagola, što prema nekim znanstvenicima čini najveću morfološku inovaciju kršćanskoga latiniteta (usp. Sheerin, 1996: 143; Plater - White, 1926: $44-53)^{4}$.

\subsection{Sufiksacija imenica}

Biblijski latinitet ne-biblijskih tekstova vrvi imenicama koje nastaju dodavanjem novih sufiksalnih završetaka. To su:

- nomina agentis na -tor te takve klasične s novim značenjem (usp. Plater - White, 1926: 44; Sheerin, 1996: 142): amator, adiutor, assessor, auctor, cognitor, colator, confessor, contemptor, corruptor, creator, cultor, curator, defensor, destructor, dilector, habitator, illuminator, invasor, lector, miserator, navigator, negator, ostensor, peccator, persecutor, piscator, praesumptor, probator, propitiator, protector, recuperator, salvator (prijevod grč. $\Sigma \omega \tau \eta \dot{~} \rho$, usp. Mohrmann, 1961: 24), sanctificator, sectator, seductor, triumphator, violator...

- nomina actionis na -tio/-sio i -tas, kao i takve klasične s promijenjenim značenjem (usp. Plater - White, 1926: 45; Sheerin, 1996: 142): accensio, adquisitio, aedificatio, agnitio, benedictio, caritas,

Kod navedenih autora najviše je prostora u odjeljcima o morfologiji dano upravo novim sufiksima karakterističnima za kršćanski latinitet, što se može protumačiti time da se kod drugih, gore navedenih, primjera ne nalaze nikakva nova otkrića. 
castitas, cognitio, commemoratio, confessio, corruptio, curatio, decollatio, delectatio, deprecatio, dispositio, distractio, diversitas, divinitas, dubietas, facultas, habitatio, humanitas, incantatio, infirmitas, inquisitio, insultatio, integritas, interventio, iussio, lamentatio, lectio, maiestas, mentio, mortificatio, narratio, navigatio, operatio, passio, paupertas, perdictio, perditio, peregrinatio, persecutio, possessio, posteritas, praedicatio, praefatio, praevaricatio, prolyxitas, prophetatio, provocatio, purificatio, relatio, remuneratio, restauratio, resurrectio, salvatio, sanatio, sanctificatio, securitas, seditio, trinitas, unitas, vanitas, virgninitas, visitatio, vivificatio, voluntas...

- obilata upotreba klasičnih deminutiva (usp. Plater - White, 1926: 42): corpusculum, cubiculus, habitaculum, incunabulum, infantulus, vasculum, vehiculus, vocabulum...

- imenice srednjega roda na -men i -mentum (usp. Plater - White, 1926: 46; Sheerin, 1996: 142): adoramentum, argumentum, fundamentum, medicamen, medicamentum, sacramentum, tormentum, vestimentum, volumen...

- apstraktne imenice ženskoga roda na -do, -go, -antia, -entia, -ura, (usp. Plater - White, 1926: 45 - 46; Sheerin, 1996: 142) te takve klasične s promijenjenim značenjem: affluentia, ignorantia, infantia, poenitentia, precatura, sollicitudo, scriptura, turpitudo...

- nove imenice i KL imenice s promijenjenim značenjem na -us i -um (usp. Plater - White, 1926: 45 - 46; Sheerin, 1996: 142): angelus, apostolus, catholicus, desiderium, episcopus, evangelium, martyrium, mercimonium, muiltipharium, mysterium, natatorius, natatorium, paraliticus, pharisaeus, pontificatus, probaticus, sacramentum (grč. $\mu$ votípıov ${ }^{5}$ ), sacrificium, spiritus (prijevod grč. $\left.\pi v \varepsilon \tilde{v} \mu \alpha^{6}\right) \ldots$

O semantičkoj razlici (lat. Sacramentum - grč. Muбtท́pıov) vidi Mohrmann (1977: 148 - 149).

6 Vidi Mohrmann (1961: 25) za detaljnije tumačenje prijevoda grč. $\pi v \varepsilon \tilde{v} \mu \alpha \mathrm{u}$ lat. spiritus. Također, usp. Mohrmann (1977: 148), o semantici: „There were innovations in the field of 


\subsection{Sintaksa padeža}

U sljedećem poglavlju, uz padeže, promatraju se i prijedložne fraze. One se pojavljuju umjesto prijedloga, primjerice in ore, in conspectu, de manu, a facie, ad faciem i sl. (usp. Sheerin, 1996: 146). To se pripisuje utjecaju hebrejskoga jezika, primjerice: inspuit in faciem eorum dicens f. VIr; Ne proicias me a facie tua, Domine f.VIv. Usto, kod dativa ne primjećujemo nikakve nove upotrebe koje bi upućivale na prijevode $\mathrm{s}$ grčkoga ili hebrejskoga jezika, stoga je njegova analiza izostavljena.

\subsubsection{Nominativ}

Ponajviše je primijećena pojava "nezavisnoga nominativa“, tzv. nominativus pendens, koji redovito stoji iza ecce (grč. íooú)7. Takav nominativ pripisuje se utjecaju hebrejskoga jezika. Primjerice: Pasional: Ecce mulier mea lecto tenet ... f. 156v; Ecce cultor aeternitatis, advenit Nicolaus...f.VIIIIv; Ecce infantulus ille cum facula aperuit ei fenestram dicens ... f.106v; Ecce eruditus es de omnibus quę fecit Iesus.. f. 156v; Ecce sancta coniuncxit mulier stansque in ripam fluminis f. 266r, Ecce Deus vester! Ecce Deus in fortitudine veniet... Ecce merces eius cum eo ... Ecce gentes quasi stille ... Ecce insule quasi puluis exiguus! f. XXXv.

\subsubsection{Genitiv}

Sintaksa genitiva stabilno čuva klasičnu upotrebu, uz utjecaje prijevoda s hebrejskoga jezika. Ne slijedi vulgarnolatinsku praksu prema kojoj se ovaj padež s vremenom zamijenio ablativom i prijedlogom de. Primjerice, očuvan je klasični genitiv uz imenice; genitiv objektni (persecutio nostri, amator Christi, cultor aeternitatis, consultor legis, cultor Trinitatis, ludificator populi, sponsio veritatis, praevaricator legis, violator castitatis), genitiv dijelni (primus civitatis), genitiv posvojni (magnalia Salvatoris, vasculum olei, magnalia Dei, famulus Dei, itinera maris,

semantics: existing words adopted - in the circles of Christians - a new meaning, whereas in the general, common language, they kept their old meaning“.

7 Za nominativus pendens usp. Plater-White (1926: 19, 80). Smatraju da ovakav nominativ možda potječe iz hebrejskoga jezika. Dalje, vidi Sheerin (1996: 146 - 148) o upotrebi ecce. 
benignitas Creatoris, templum Dei, sedes Spiritus Sancti), genitiv materije (statua salis) i genitiv svojstva (pontifex magnae auctoritatis).

Od novih funkcija genitiva uočena je pojava tzv. genitiva „intenzifikacije" odnosno pojačavanja prve imenice ${ }^{8}$, što se pripisuje utjecaju hebrejskoga jezika. Ovaj je genitiv osobito čest u biblijskome latinitetu Vulgate, a u tekstovima u Pasionalu vidljiv je uglavnom na primjeru secula seculorum (redovito na kraju pasija). Upotrebljava se genitiv usporedbe (usp. Sheerin, 1996: 147) kao odraz grčkoga jezika, primjerice et ipse faciet et maiora horum faciet $\mathrm{f}$. XIr.

Bilježimo i pomaknutu upotrebu genitiva kvalitativnoga uz koji, umjesto pridjeva, dolaze imenice (usp. Plater - White, 1926: 93; Sheerin, 1996: 146; Blaise, 1955: 82). Ovaj genitiv uočen je u oba dijela $M R$ 164, a pripisuje se utjecaju hebrejskoga jezika, primjerice: baptismum poenitentiae, corona certaminis, fama bonitatis, hictus coruscationis, vas electionis ${ }^{9}$, lignum concupiscientiae, lignum crucis, lignum passionis, lignum praevaricationis, misterium crucis, oleum parvitatis, passio crucis, signum vulneris, templum antiquitatis, vasculum olei, via salutis, vox petitionis...

Zabilježena je pojava određenih imenica u ablativu koje se upotrebljavaju s genitivom i imaju funkciju prijedloga (usp. Blaise, 1955: 94), što nije neuobičajeno ni za klasični latinitet, ali u biblijskome ima širu upotrebu. Razlika između upotrebe u KL i VL jest ta što biblijski latinitet, shodno i slobodnijemu redu riječi u rečenici, stavlja imenicu u ablativu pred imenicu u genitivu, primjerice: causa sepulture eius f. $48 \mathrm{v}$; causa edificationis, causa mercationis f. XIIr, causa experientiae f. VIIv, medendi causa f.49r, gratia divinitatis f.231r... Ova pojava uočena je u oba dijela $M R 164$.

\footnotetext{
8 Vidi Plater-White (1926: 20). Usp. Sheerin (1996: 146); navodi kao "genitive for intensification". Tzv. genitiv intenzifikacije prijevod je autora.

$9 \quad$ Primjer koji je često navođen u literaturi. Usp. Sheerin (1996: 146); Blaise (1955: 82).
} 


\subsubsection{Akuzativ (s prijedlozima)}

Akuzativ generalno bilježi klasičnu sintaktičku upotrebu, no ujedno se zamjećuje da je češće upotrebljavan u analitičkoj tvorbi s prijedlozima. Uočena je prekomjerna upotreba prijedloga in s akuzativom kao prijevod s hebrejskoga jezika u značenju $u$, do (usp. Sheerin, 1996: 146), ali ne $\mathrm{u}$ prostorno-vremenskome značenju, primjerice: fellea face succensus, magnam contra Nicolaum exarsit in iram et novo pectore, f. XIr; Quibus auditis, vir Dei, solito more, in laudem prorupit clementissimi patris ac deinde $\mathrm{f}$. XIv; et si corpus meum in potestatem habes, animam autem meam non habet(!) ${ }^{10}$ in potestatem f. 133v.

Za razliku od uobičajene prakse vulgarnoga latiniteta na kojemu se temelji biblijski latinitet (usp. Grandgent, 1907: 78), u MR 164 postoji dobra očuvanost značenja prijedloga in u vidu kretanja (akuzativ i in), pri čemu se održava klasična funkcija. ${ }^{11} \mathrm{U}$ skladu s tim, akuzativ cilja sačuvan je, nije izgubljen kao u VL: veniens Petrus in urbem Romam f. 156r; iactavit in faciem patris sui f. 115; reversa in domum suam f. XXIIIIr; in exilium direxit f. 153v; iussit in carcerem retrudi f. 156; te habe in tenebras exteriores f. 116v; iussit duci in viam Aureliam f. 119; respiciens in $\underline{\text { celum }}$ f. 118r; (ali postoje i izuzetci, primjerice veniens in pretorio f. 117v). Konačno, ovaj padež dobro je sačuvan u konstrukciji akuzativa s infinitivom ( $t u$ filias tuas fornicari mandabas? f. VIIIIr.).

\subsubsection{Ablativ (s prijedlozima)}

Ablativ čuva klasičnu sintaksu, ali i dolazi s prijedlozima, slijedeći tako praksu vulgarnoga latiniteta (usp. Grandgent, 1907: 45). Primjeri su klasične sintakse: ablativ vremena i trajanja (usp. Blaise, 1955: 91), primjerice: manebit paucis diebus, multo tempore iacuit, temporibus Dioclitiani et Maximiani imperatorum, eodem tempore quo Liberius papa, primo tempore alleluiata est terra...; ablativ obzira (usp. Blaise, 1955:

Treba stajati habes.

${ }^{11}$ Odstupanja od prakse VL, kao uostalom i sva nabrojana odstupanja od prakse KL, naglašavaju se kako bi se uvidjelo da biblijski latinitet ne-biblijskih tekstova nije utemeljen isključivo na konstrukcijama VL, nego ga čini kombinacija morfosintaktičkih karakterizacija i VL i KL. 
90), primjerice, pulcra facie, sed pulcrior fide, f. 84v; ablativ uzroka, primjerice: consilio, rite, voluntate, necessitate, sonitu excitatus homo. Obilato je korišten u konstrukciji ablativa apsolutnoga.

Sintaktički ablativ vremena korišten je gotovo uvijek na početku pasija. Primjerice: temporibus imperatoris Maximiani erat $\mathrm{f}$. Vv, temporibus Diocletiani et Maximiani f. XXVIIv, temporibus Claudii imperatoris venit quidam vir f. 67v, temporibus Iuliani impiissimi imperatoris f. 112v, in diebus Decii Cesaris urbis Rome multe persecutiones erant adversus Christianos f. 13ov, eodiem die Decius Cesar et Valentianus prefectus f. 173 r.

U upotrebi s prijedlozima uočava se široko shvaćeno značenje prijedloga $d e^{12}$ i $e x^{13}$. Tim prijedložnim izrazima zamjenjuje se klasična sintaksa ablativa. Ujedno, ovi prijedlozi obuhvatili su i značenje prijedloga propter, $a / a b$ i $o b$. U tome smislu de i ex dolaze u:

- uzročnome značenju „zbog, radi/poradi“: de corruptione (zbog) f. XXIr; de pollutione (zbog) f. XXIr, de medicamento (zbog) f.XXIIIv, gaudebat populus cunctus de tali patrono $\mathrm{f}$. Xv;

- u značenju odvajanja „s/sa“: filius Dei de celo descendens $\mathrm{f}$. XXVIv, ascendissent de navi $\mathrm{f}$. XXv, vocem de caelo audivit f.Xr, nullus ex eis (zamjenjuje se gen. partitivni) f. XXVIIIr;

- u kvalitativnome značenju svojstva, prevodeći ga s „od“: statua solis facta ex auro f. XXVv;

- u komparativnome značenju „od“ umjesto klasičnoga quam: Quomodo habundantius inluminant tres fenestre de duobus? f. VIr;

- u značenju odvajanja „iz“: de urbe Roma f. XXVIIv; omnes homines de uno patre et de una matre f. 226r, ut tollam indignationem de animo tuo f. $42 \mathrm{r}$.

Dalje, uočava se upotreba prijedloga in s ablativom $\mathrm{u}$ instrumentalnome i/ili uzročno-instrumentalnome smislu (usp. Sheerin, 1996: 146)

${ }_{12}$ Usp. Plater - White (1926: 99); objašnjavaju de i $e$, ex sljedećim: „from, concerning, of (partitive); out of, from", napominjući: ,it is often hard to see any distinction between the use of de and of $e x . "$

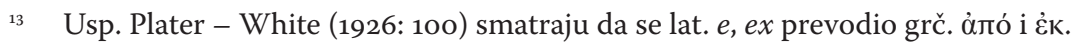


kao utjecaj hebrejskoga jezika (koji se još može protumačiti i kao prijevod grč. $\dot{\varepsilon} v$, usp. Plater - White, 1926: 21), kao izrazita karakteristika vrlo česte upotrebe: et baptizetur unusquisquam in confessione sua f. 69r, in bonitate conspicuus, in universa morum honestate preclarus f. 7or, dives enim in omnibus Christus est f. 74r, ite in nomine meo f. 122r, turbatur tota civitas in tremore f. 126v, tu enim dixisti in evangelica voce f. 127r, ne tardes me baptizare in nomine eius f. 129r, baptizati vero permanete in fide f. 131v, et crediderunt in Domino f. 133r; Non statim scelestos percutit, nec perdit in crimine f. VIIv.

Osobito je česta upotreba prijedloga in s ablativom za doslovan prijevod grčkoga prijedloga غ̇v i supstantiviranoga infinitiva ${ }^{14}:$ In suscipiendis hominibus humilem, in loquendo efficacem se praebebat. Alacer erat in exhortando, severus in corripiendo. f. IXv

Dobra je očuvanost značenja prijedloga in u vidu bivanja (ablativi in), pri čemu se ne održava praksa vulgarnoga latiniteta, gdje se kod ovoga prijedloga nije razlikovao pojam kretanja od mirovanja (usp. Grandgent, 1907: 78). Primjerice: Interea in domo tribuni f. 157r; ligata autem sancta Christina in rota f. 114r; erat autem in civitate f. 159r; stans in fenestra f.114r; notabat in corde suo f. 114r; in fenestra incumbens f. 114r.

\subsection{Upotreba zamjenica}

U tekstovima koji svoj jezični ustroj temelje na prijevodima Septuaginte, poput tekstova Pasionala, odsutnost člana pred imenicom u latinskome jeziku uzrokovala je niz problema pri prevođenju (usp. Väänänen, 1967: 129, \$275).

Sv. Jeronim i njegova škola su za potrebe prijevoda grčkoga određenog i neodređenog člana koristili latinske pokazne zamjenice (usp. Blaise, 1955: 101, \$131; Sheerin, 1996: 146), stoga se osobita pažnja pridaje njihovu tumačenju i raskoraku između njihovih klasičnih i vulgarnolatinskih uloga. Kod ostalih zamjenica nisu opažena veća odstupanja. ${ }^{15}$

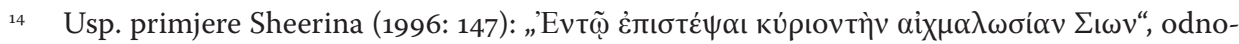

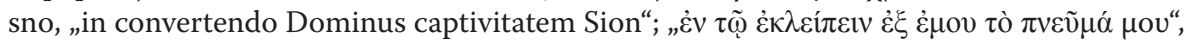
odnosno, „in deficiendo ex me spiritum meum.“

15 Vidi Väänänen (1967: 128) i dalje, a osobito je pregledan grafički prikaz na str. 129. 
U Pasionalu generalno bilježimo pleonastičku upotrebu pokaznih zamjenica (usp. Blaise, 1955: 101, \$132; Sheerin, 1996: 148), prvenstveno zbog prijevoda grčkoga člana (usp. Blaise, 1955: 102, \$133; Sheerin, 1996: 147), potom zbog nerazlikovanja njihova značenja ${ }^{16}$, miješanja funkcija (usp. Blaise, 1955: 103, \$136, 137; Sheerin, 1996: 148) i emfatičke upotrebe (usp. Blaise, 1955: 101, \$132).

Primjerice: Ipse vero convocans filiam suam, dicit ei: "Filia, tu imperasti tres fenestras statuere?" Ipsa vero dicit ei: ... f. VIr; Orabat vero beata Barbara et abscisa est petra et suscepit eam intus et eiecit eam super montem. f. VIr; Respondens beata martyr Christi Barbara dicit: „Ego habeo Dominum meum ... f. VIv; Et tenens comam capitis eius, pertraxit eam a monte et reclusit eam in cellulam et munivit clavibus. f. VIr; Ascendens vero pater eius interrogabate os de ea. f. VIv.

Vidljivo je da se grčki neodređeni član prevodi pomoću latinskoga unus (Pasional: Facite et instruite mihi et aliam unam fenestram! f. VIr), a određeni član pomoću is/ea/id, hic/haec/hoc, ille/illa/illud i ipse/ ipsa/ipsum (primjeri niže navedeni po natuknicama, usp. Sheerin, 1996: 148). ${ }^{17}$

Slijedi pregled upotrebe pokaznih zamjenica:

- hic: dijelom zadržava klasično značenje (što se na određenim mjestima vidi iz korelacije sa zamjenicom ille (ovaj - onaj), primjerice: O nova Iacob stropha! Ille commentatus est, qualiter Laban, mercedem suam non admitteret. Hic, autem, ut cęlestibus non privaretur commodis. Ille in canalibus decorticatas ponebat virgas, ut varia quaeque acciperet. $\mathrm{Hic}$, ut Helisii varia oblectamenta quiverit adipisci, edis in claustra intra ligatum proiecit obrizum. Hic est, Iesus magister bone tuus non surdus auditor, qui iussis obtemperans tuis, duo implevit praecepta. f. VIIIv). Potom, od novih upotreba katkad dolazi umjesto iste (usp. Blaise, 1955: 104) i umjesto is, ${ }^{18}$ što implicira nerazumijevanje značenja, primjerice: "Hic de quo loquimur Iesus erat Deus, et est in eternum." f. 158r.

16 Usp. Blaise (1955: 103, \$137). Slično opaža i Skok (1952: 250): „U sintaksi zamjenica najvažnije odstupanje od klas. latiniteta tiče se zamjenica ille i ipse. Kao u romanskim jezicima ona i ovdje zamjenjuje is, ea, id." Vidi i Harrington (2007: 100); vidi Sheerin (1996: 147).

${ }_{17}$ Vrlo detaljan prikaz zamjene grčkoga člana latinskim zamjenicama u latinitetu Biblije. Usp. Plater-White, (1926: 78) i dalje. Usp. Blaise (1955: 102, \$133).

18 Usp. grafički prikaz kod Väänänen (1967: 129). 
Još, u direktnome obraćanju služi kao demonstrativ 2. l. jedn. (tu) (usp. Blaise, 1955: 104).

- ille: zadržava klasično značenje i ponaša se kao osobna zamjenica 3. l. jednine (usp. Blaise, 1955: 105; Väänänen, 1967: 129), primjerice: At ille ait: "Si me sanum fecerit...", quod si ille salvus esset, omnes crederent Christo f. 98r; At illi: „Pater" inquiunt „sancte, pacifici sumus..."f. XIIr; At illi seriatim cuncta narrantes: „En“ aiunt et oleum ostendunt... f. XIv; uzima pokazno značenje bližega objekta (miješanje značenja): coepit bonae indolis adolescens esse et non, sicut illa aetas assolet... f. VIIIr.

- is: uglavnom zadržava klasično značenje, ima primjera gdje se ponaša se kao refleksivna zamjenica (usp. Blaise, 1955: 108), primjerice: Tantam vero in $\underline{s e}^{19}$ credentibus tribuit virtutem f. $158 \mathrm{r}$.

- idem: osim što se javlja u klasičnome značenju, dolazi umjesto is, primjerice: Dicit eisdem famula Dei Barbara: ...f. VIr; Multi vero nobiles dabant filios suos beato Apollenari, ut ab eodem sacras litteras erudirentur. f. 157r; Non enim parva multitudo ab eodem seducta... f. $159 \mathrm{v}$.

- ipse: dolazi u klasičnoj upotrebi: ... tradidit eum in custodiam cuidam centurioni, qui et ipse iam Christianus erat occulte cogitans... f. 160r; Sacrificium me ipsum offero pro salute filiorum meorum... f. 160r; ut ipse cognoscam vera esse que dicis. f. 165v; Interea ipse tribunus cum uxore et filiis et familia sua credentes in Jesum, baptizati sunt. f.157r; umjesto is ${ }^{20}$ (usp. Blaise, 1955: 108; Väänänen, 1967: 129): Ipse vero fiduciam habens in Dominum Iesum accessit et tettigit puellam dicens... f. 158r; Igitur post hęc Ruphus patricius, timens Cesarem et ministrabat ei, filia vero ipsius... f. 158r; ipse est Deus meus. f. 158r; et preter ipsum non est alius, f. 98r; et proiecit eum in semine in cilicio, in quo ipse orare consueuerat... $\mathrm{f}$.

19 Usp. Rigg (1996: 86): „Medieval Latin usage of the reflexives se and suus is often careless by classical standards."

2o Usp. Skok (1952: 250): „Mjesto zamjenica is, hic, ille upotrebljava se često ipse u istom značenju." 
98v; et ab ipso inhanc ${ }^{21}$ felicissimam urbem directus sum... f. 160r. Bilježi se i česta emfatička upotreba ${ }^{22}$ (usp. Blaise, 1955: 108): semet ipsum et incarnatus est de Spiritu Sancto f. 158r; Sacrificium me ipsum offero pro salute filiorum meorum f. 160r; Spiritum Sanctum in semet ipsam recipiet, f.98r; ipsum misterium crucis in temet ipsum excipies. f. Iv.

\subsection{Pridjevi i komparacija}

Pojavljuje se nova sufiksacija kod pridjeva na -(bi)lis, -atus, -itus i negativi na -in (usp. Plater - White, 1926: 48; Sheerin, 1996: 142), ujedno se bilježi i upotreba klasičnih s novim značenjem: argumentosus, auratus, carnalis (grč. $\sigma \alpha ́ \rho \xi)$, contemplatus, corporalis, corruptibilis, damnaticus, damnatus, divinitus, excaecatus, gentilis, illuminis, immaculatus, immortalis, incommutabilis, incorruptibilis, incomprehensibilis, irrationabilis, invisibilis, sacerdotalis, sanctus, sanctificatus, spiritusanctus, peccatus, potentatus, propheticus, provolutus, purificatus, repropitiatus, vinctus... (uočavaju se posebne skupine pridjeva na jednome mjestu u tekstu, npr. koji označavaju bolesnike: caecus, claudicans, infirmus, lunaticus, mancus, mutus, paraliticus, sordus).

Osobito je često upotrebljavan elativ ${ }^{23}$, što je karakteristika i KL, ali frekvencija upotrebe u biblijskome latinitetu ne-biblijskih tekstova privlači pažnju, primjerice: clementissimus/sacratissimus/excellentissimus imperator, Agathes letissima, beatissima martyr/virgo, beatissimus evangelista, pessimus demon, summus/imus Deus, vanissimus lupus, Paschasius miserrimus; quem cum rex alacri animo et vultu placidissi$\underline{\text { mo }}$ suscepisset $\mathrm{f}$. 5or; Martyrizata est autem sanctissima martyr Christi Barbara f. VIv; Haec igitur fortissima martyr fide circumornata vicit diabolum. f. VIr; Igitur milites circumduxerunt eam in predium voca-

${ }_{21}$ Slovo $n$ napisano je iznad svojega mjesta.

${ }_{22}$ Usp. što o demonstrativnoj čestici -met misli Grandgent (1907: 14): „... met were used as demonstrative prefixes to pronominal adjectives and to adverbs. ... Met, primarily a suffix, came to be used as a prefix through such combinations as semetipsum, ..."

${ }^{23}$ U literaturi se spominje raznovrsna upotreba superlativa, vidi Blaise (1955: 97) i dalje. O apsolutnoj upotrebi superlativa u pučkome govoru vidi Väänänen (1967: 126). 
tur Dilasium in loco Solis ad impiissimum presidem. f. VIr; vir Dei solito more in laudem prorupit clementissimi patris ac deinde... f. XIv; postquam longissima maris itinera transfretarunt et pontum sulcarunt Lyciae regionis... f. XIr; Cruentissime, quare non attendisti dominicam praeceptionem... f. XIIv;

Upotrebljava se genitiv usporedbe (usp. Sheerin, 1996: 147) kao odraz grčkoga jezika, primjerice et ipse faciet et maiora horum faciet $\mathrm{f}$. XIr.

\section{Zaključak}

Tekst o derivaciji, fleksiji i sintaksi imenā u biblijskome latinitetu ne-biblijskih tekstova nastoji rastumačiti nomen i njegovu poziciju $\mathrm{u}$ tome ogranku kršćanskoga latiniteta. Primjeri navedeni u radu dokazuju da je biblijski latinitet ne-biblijskih tekstova vulgarni latinitet i kao takav može se opisati shodno postojećim udžbenicima, kako našim (usp. Tekavčić, 1970) tako i stranim (usp. Grandgent, 1907; Blaise, 1955; Väänänen, 1967). Ujedno, rad nije pokazao da je ova inačica kršćanskoga latiniteta poseban jezični sustav unutar srednjovjekovnoga latiniteta, kako je to dokazivala jedna grupacija stranih znanstvenika sredinom prošloga stoljeća. Tezu da je kršćanski latinitet tzv. langue spéciale razvila je C. Mohrmann (usp. Mohrmann, 1977: 30, 96) nakon što je njezin fakultetski profesor i nizozemski filolog J. Schrijnen prvi predstavio to mišljenje. Tijekom godina Mohrmann je implementirala teoriju o posebnosti i autonomnosti ove inačice latiniteta unutar srednjovjekovnoga, ali nije naišla na velik broj istomišljenika. Radovi u kojima je tumačila da je kršćanski latinitet autonoman i poseban jezični idiom uspjeli su predstaviti posebnosti ove inačice latiniteta tek s obzirom na semantiku, prijevodna rješenja s grčkoga i hebrejskoga na latinski jezik, bogati vokabular, frazarij i jedinstveni sociolingvistički položaj. S obzirom na te diskusije i postojeću literaturu iz vulgarnoga latiniteta, ovim radom može se potvrditi da je biblijski latinitet ne-biblijskih tekstova temeljen isključivo na vulgarnome latinitetu. 


\section{Appendix}

Passio sancte Barbare

f.Vv /ds/

Incipit passio beatissime martyris Christi Barbare.

Temporibus imperatoris Maximiani, erat quidam satrapas nomine Dioscurus dives valde, paganus vero existens et colens hydola. Hic habuit filiam unicam nomine Barbaram. Fecit autem pater eius turrem sublimem ibique reclusit eam, ita ut non videretur ab hominibus, propter eminentem pulchritudinem eius. Locuti sunt quidam de optimatibus patri eius de ea ut nurum sibi acciperet.

Ipse vero accedens in turrem persuadebat eam dicens:

„Filia mea, quidam de potentibus commemorati sunt me de te ut acciperent te in coniugium. Quid ergo velis de hoc?"

Ipsa vero intuita cum ira dixit: „Ne cogas me de hoc agere pater!“

At vero ipse secessit ab ea et descedens permanebat in quo condebatur ab eo lavachrum. Instituerat enim multitudinem artificium quatinus hoc cito perficeretur instituens vero quomodo debuit fieri. f.VIr (ls) Et tribuens singulis propriam mercedem in integro profectus est regionem longinquam, faciens ibidem tempus non modicum. Descedens vero famula Dei Barbara de turre videre opus quod factum est, et vidit contra septemtrionem duas solum modo fenestras instituistas, <et dixit artificibus: "Quare duas solum modo instituistis?">

Dicunt ei: „Pater tuus sic nobis distribuit."

Dicit eis beata Barbara: „Facite et instruite mihi et aliam unam fenestram!"

Ipsi vero dicunt ei: „Timemus, domina, ne quando indignabitur pater tuus nos adversus nos, et non possumus portare eum."

Dicit eisdem famula Dei Barbara: „Quod dico vobis facite! Ego de hoc adquiescere faciam patrem meum."

Ipsi vero adquieverunt ei ut aliam fenestram facerent sicut constituit eis. Perambulans vero inquirrulosa et inmaculata Barbara in natatorio et abiens contra instituit in armoribus digito pretiosam crucem in figura eius usque in hodiernum diem ad conpunctionem intuentium. 
Ingressa vero ea in absidem in qua ingrediebatur sanctificata aqua facta est figura pretioso eius pede, in quo omnes sanationes et salutes eorum mensura acceperunt. In hoc enim lavachro sanctam eius verticem suscepit sanctam baptisma locusta melle alito et pręconem ac precursorem seu Baptista Iohannem. Hoc lavachro similabitur fontis Syloe, in qua qui a nativitate cecus lavans respexit hoc lavacrum similabitur probatica natatoria in qua paraliticus verbo curatus est. Haec est natatoria fons incorruptibilis. Hec est natatoria quę curant omnem languorem et omnem infirmitatem. Haec est natatoria aqua viva quam Samaritana petivit de sanissimo natatorio. Pertransiens vero agnam Christi Barbara et ascendens in turrem vidit/ds/ simulacra que colebat pater eius et suscipiens Spiritum Sanctum multipharia bene mobile desertum incontaminatum luculentum, intactum benignum acutissimum beneficium certum diligentissimum securum cuncta super inspectum. Circuivit enim ea vapor Dei virtutis et affluentia de Omnipotentis gloriae sinceritate. Haec igitur fortissima martyr fide circumornata vicit diabolum. Haec igitur videns sordida simulacra inspuit in faciem eorum dicens: „Similes vestri fiunt qui faciunt vos et omnes qui confidunt in eis." Et ascendens in turrem erat ibidem precatura Dominum.

Finito autem opere atque perfecto reversus pater eius de peregrinatione et contemplatus: „Tres fenestras instituistis?“

Dicunt ei artifices: „Filia tua sic nobis pręcepit.“

Ipse vero convocans filiam suam dicit ei: „Filia, tu imperasti tres fenestras statuere?"

Ipsa vero dicit ei: „Etiam et enim benefeci. Nam tres fenestre inluminant omnem hominem at vero due tenebrescunt."

Et adsumens eam pater eius descendit in natatorium et dicit ei: „Quomodo habundantius inluminant tres fenestre de duobus?"

Beata Barbara respondit: „Haec sunt Pater et Filius et Spiritus Sanctus."

Tunc repletus est furore pater eius et tulit spatam suam ut occideret eam. Orabat vero beata Barbara et abscisa est petra et suscepit eam intus et eiecit eam super montem. Erant autem duo pastores pascentes oves in eodem monte, qui et viderunt eam fugientem in montem. Ascendens 
vero pater eius interrogabat f.VIv /ls/ eos de ea. Et quidem unus volens salvare eam cum iuramento negavit quod non vidisset. Alius vero digito demonstravit eam. Et maledixit eum beata Barbara. Et statim factę sunt oves eius locustę que et permanent pretiosum eius sepulchrum usque in hodiernum diem. At vero pater eius reperiens eam flagellavit. Et tenens comam capitis eius pertraxit eam a monte et reclusit eam in cellulam et munivit clavibus, instituit catenas ut non apperiret ei quisquam. Constituens et custodes usque dum abiens nuntiaret presidi ut tradat eam ad torquendum. Adveniens vero preses iussit offerri eam. Ingressus vero pater eius una cum Gerontio Commentariense eiecit eam de cella et tradidit eam presidi, adiurans eum per deorum potentiam ut atrocibus tormentis eam consumeret. Tunc preses sedens pro tribunali et videns pulchritudinem eius dicit ei: „Quid vis? Parce tibi ipsi et sacrifica diis aut accerrimis tormentis traderis!"

Respondens beata martyr Christi Barbara dicit: „Ego habeo Dominum meum cui sacrificare debeo Iesu Christo qui fecit cęlum et terram mare et omnia quę in eis sunt. Demonia enim tua, ut propheta dicit: „Os habent et non loquentur, oculos habent et non videbunt, aures habent et non audient, nares habent et non odorabunt, manus habent et non palpabunt, pedes habent et non ambulabunt, non clamabunt in gutture suo, neque enim est Spiritus in hore ipsorum. Similes illis fiant qui faciunt ea et omnes /ds/ qui confidunt in eis."

Tunc preses repletus furore iussit expoliari eam carnis eius nervis discerpere et cilicinis textis defricare, qua illate sunt ei plage, ita ut omnem corpus eius inquinaretur sanguini et iussit ut recluderetur in carcere donec tractaret de ea qua pena consumeret eam.

Media vero nocte circumfulsit eam lux de celo, in qua apparuit ei Salvator dicens: „Confide atque confortare, Barbara, quoniam copiosum gaudium sit in cęlo et in terra super tuam passionem! Non ergo metuas minas tyranni, ego enim sum tecum et ego eruam te ab omnibus plagis que inferunt tibi.“

Et statim omnes plage nusquam comparuerunt ab ea. Et hęc dicens Dominus adsignavit eam et ascendit in cęlos. Gaudebat autem et exultabat martyr Christi Barbara super exortatione Domini. Mane autem 
facto iussit afferri eam et intuens preses que inlata sunt ei tormenta nusquam comparuerunt.

Dicit ei: „Ecce quomodo repropitiati sunt tibi dii et diligunt te, Barbara, quia plagas tuas sanaverunt?"

Respondens autem martyr Christi Barbara dicit presidi: „Similes sunt dii tui surdi et muti et cęci, et sine intellectu et immobiles, et quomodo habebant plagas meas curare, remedium sibi ipsis non potentes adhibere? Me autem quem curavit Iesus est Christus Filius Dei vivi quem tu non vides, eo quod cor tuum induratum est a diabolo."

Tunc iratus pęrses et fremens ut leo iussit carpere latera eius et lampadas ardentes applicari ei et malleo super caput eius cędi.

Ipsa vero intuita in cęlum dixit: „Tu nosti cordis cognitor Christe, quoniam amoris tui accensione hęc patior. Neme ergo derelinquas, f.VII, /ls/ pro te vero has plagas fortiter sustinui.“

Iussit impius pręses gladio abscidi mamillas eius. Amputatis vero uberibus eius martyra Christi Barbara aspiciens in cęlum dicebat: „Ne proicias me a facie tua, Domine, et Spiritum Sanctum tuum ne auferas a me!"

Cum autem et hanc plagam fortiter sustinuit, iussit impius preses nudam eam circuire omnem regionem illam et plagis inferentibus flagellari eam.

At vero martira Christi Barbara intuita in celum dixit: „Domine Deus, qui operis celum nubibus, protector et adiutor meus esto, et tege nudatum corpus meum ut non videatur a visu virorum impiorum."

Et hęc dicente ea venit Dominus super currum Cherubim et mittens angelum suum qui operuit eam stola candida. Igitur milites circumduxerunt eam in predium qui vocatur Dilasium in loco Solis ad impiissimum presidem. Precepit quoque preses per gladium eam tradi. Tunc furore repletus pater eius suscepit eam a preside et perduxit eam in montem. At vero martyr Christi gaudens super hoc festinabat ut perfectum victorie bravium acciperet.

Et ducta adhortabat martyrii coronam dicens: „Domine Iesu Christe, qui cęlos extendisti et terram fundasti, qui abissos conclusisti et mari murum posuisti, qui precepisti umbriferas nubes pluere super bonos 
ac malos, qui super mare ambulasti, qui increpasti tumentem ventum! Omnia enim obediunt tibi! Domine Iesu Christę, presta mihi petitionem hanc et da famulę tuę gratiam, ut si qui memoraverit in nomine tuo nomen famulę tuę faciens memoriam famulę tuę die martiri mei? Domine, ne memineris peccatorum eorum in die iudicii et propitiare eorum /ds/ peccatis. Tu enim nosti Domine quia caro sumus." Et dicente ea: „Amen."

Facta est vox Domini ad eam dicens: „Veni, pulcherrima mea, ad leta! Requiesce in cubilibus patris mei qui est in cęlis! De quantu autem postulasti donatum est tibi. Amen."

Hec exaudiens martyr Christi venit ad locum predictum et illic finita est deprecatio eius, martyrium accepit, a suo patre decollata est.

Et completum est martyrum eius in boni confessione cum sancta Iuliana in eodem loco. Descendente vero patre eius a monte, ignis cecidit de celo et combussit eum ita ut nec pulvis eius inveniretur.

Finita est autem sancta martyr Christi Barbara cum sancta Iuliana quarto die mensis Decembris. Valentinus fuero quidam venerabilis petiit veneranda corpora sanctorum martyrum, et reposuit in loco solis in habitaculum modicum in quo sanationes plurime celebrantur in gloria Dei Omnipotentis.

Martyrizata est autem sanctissima martyr Christi Barbara imperante Maximiano Augusto et preside Marciano, apud nos vero regnante Domino Deo atque salvatore nostro Iesu Christo, cui est honor et gloria in saecula saeculorum. Amen.

Explicit passio Sancte Barbare.

\section{Literatura}

- Badurina, AnĐelko i dr. (1983) Umjetnost na tlu Jugoslavije: Minijatura, Jugoslavija - Spektar - Prva književna komuna, Beograd - Zagreb - Mostar, str. 22 - 32.

- Blaise, Albert (1955) Manuel du Latin Chrétien, Le Latin Chrétien, Strasbourg. 
- Grandgent, Charles Hall (1907) An Introduction to Vulgar Latin, D. C. Heath\&co., Boston.

- Harrington, Karl Pomeroy (1997) Medieval Latin, The University of Chicago Press, Chicago.

- Herman, József (1970) Le Latin Vulgaire, Presses universitaires de France, Paris.

- Herman, József (cop1997) Vulgar Latin, The Pennsylvania State University Press, Pennsylvania.

- Krešić, LuCIJA (2015) Jezično-paleografska analiza kodeksa Passionale MR 164, doktorska disertacija, Zagreb.

- Matijević Sokol, Mirjana (2014) „Od Ivana Ravenjanina do Adama Parižanina. Poruke Splitskog Evangelijarija“, Splitska hagiografska baština povijest, legenda, tekst. Zbornik radova s međunarodnog znanstvenog skupa održanog u Splitu od 26. do 27. rujna 2011., Književni krug Split - Odsjek za povijest Filozofskog fakulteta u Splitu, Split, str. $69-83$.

- Mohrmann, Christine (1977) „Latin tardifet Latin mèdièval“, Études sur le Latin des Chrétiens. Tome IV, Latin Chrétienet Latin médiéval. En Appendice Jos. Schrijnen Charakteristik des Altchristlichen Latein, Edizioni di storia e letteratura, Roma, str. 29 - 47.

- MOHRMANN, CHRISTINE (1977) „L'étude du Grec et du Latin de l'antiquite Chrétienne: Passé, présent, avenir", Études sur le Latin des Chrétiens. Tome IV, Latin Chrétienet Latin médiéval. En Appendice Jos. Schrijnen Charakteristik des Altchristlichen Latein, Edizioni di storia e letteratura, Roma, str. 91 - 110.

- MOHRMANN, CHRISTINE (1977) „The Ever-recurring Problem of Language in the Church", Études sur le Latin des Chrétiens. Tome IV, Latin Chrétienet Latin médiéval. En Appendice Jos. Schrijnen Charakteristik des Altchristlichen Latein, Edizioni di storia e letteratura, Roma, str. 143 - 159 .

- NovaK, VIKTOR (1920) Scriptura beneventana s osobitim obzirom na tip dalmatinske minuskule: Paleografska studija. /s.n./, Zagreb. 
- Novak, Viktor (1963) Pojava i proširenje karolinške minuskule u Dalmaciji, Otisak iz Glasa SANU, knjiga 11. Sanu, Beograd, str. $1-63$.

- PASIONAL MR 164, karolinško-beneventanski kodeks iz Knjižnice Zagrebačke nadbiskupije Metropolitane.

- Perić, Olga (1982) „Neke jezične osobitosti djela Historia Salonitana ", Živa antika, Sojuz na družbata za antički studiji na Makedonija, Skopje, god. XXXII, br. 1, str. 93 - 103.

- Plater, William Edward - White, Henry Julian (1926) A Grammar of the Vulgate: being an introduction to the Study of the Latinity of the Vulgate Bible, Clarendon Press, Oxford.

- Rigg, Arthur George (1996) „Medieval Latin Philology“, Medieval Latin: an Introduction and Bibliographical Guide, The Catholic University of America Press, Washington, str. 71 - 78.

- Rigg, Arhur George (1996) „Morphology and Syntax“, Medieval Latin: an Introduction and Bibliographical Guide, The Catholic University of America Press, Washington, str. 83 - 92.

- Rigg, Arhur George (1996) „Orthography and Pronunciation“" Medieval Latin: an Introduction and Bibliographical Guide, The Catholic University of America Press, Washington, str. 79 - 82.

- Schrijnen, Joseph (1977) „Charakteristik des Altchristlichen Latein" Études sur le Latin des Chrétiens. Tome IV, Latin Chrétienet Latin médiéval. En Appendice Jos. Schrijnen Charakteristik des Altchristlichen Latein, Edizioni di storia e letteratura, Roma, str. $371-404$.

- Sheerin, Daniel (1996) „Christian and Biblical Latin“, Medieval Latin: an Introduction and Bibliographical Guide, The Catholic University of America Press, Washington, str. 137 - 156.

- Skok, Petar - Novak, Viktor (1952) Supetarski kartular, Jugoslavenska akademija znanosti i umjetnosti, Zagreb.

- Tekavčić, Pavao (1970) Uvod u vulgarni latinitet(s izborom tekstova), Sveučilište u Zagrebu, Zagreb. 
- VÄ̈̈NÄNEN, VEIKKO (1967) Introduction au latin vulgaire, Librairie $\mathrm{C}$. Klincksieck, Paris. 
Original scientific article Received on September 25, 2020 Accepted on April 11, 2021

LUCIJA KREŠIĆ NACEVSKI

University of Zagreb, Faculty of Croatian Studies

\section{HAGIOGRAPHIC CODEX PASSIONALE MR 164: FLEXION, DERIVATION AND SYNTAX OF THE NAMES IN BIBLICAL LATIN OF NON-BIBLICAL TEXTS - APPENDIX: PASSIO SANCTE BARBARE}

\section{Abstract}

Hagiographic codex Passionale MR 164 is considered as the oldest of Archdiocesan Library Metropolitana in Zagreb. It consists of two parts: the main one is Carolingian Passionale and the other is Beneventan appendix Secunda expositio super psalmum CXIX and Vita Marie Egipciace de Greko in Latinum translata. Hagiographic Passionale is dated in $10^{\text {th }}$ century and it is considered to be written in the east Adriatic coast, in Ravenna. Beneventan part is dated by the note of its scribe deacon Majon at the beginning of the $11^{\text {th }}$ century. It is written in Split for the needs of Split's Archdiocese and the Archbishop Paulus. The content analysis and sanctoral of Carolingian part lead MR 164 to Ravenna's church Sant' Apollinare Nuovo. The linguistic analysis confirms language of MR 164 to be the Biblical Latin of non-Biblical texts. This paper deals with flexion, derivation and syntax of the names within Biblical Latin of non-Biblical texts found in Carolingian Passionale. One of the topics considered is the independence of Biblical Latin as a special idiom, as well as its connection to Vulgar Latin. Transcription of Passio Sancte Barbare is attached to the main text of the paper.

Keywords: Biblical Latin; Passionale MR 164; medieval Latin; Vulgar Latin 